\title{
Evaluating the Task of Language Learning
}

\author{
David Rose
}

\section{Introduction}

This contribution is concerned with the needs of students who are struggling with school, particularly with regard to literacy, but discusses their difficulties in relation to wider issues in education. The discussion emerges from the experience of a long-term action research project known as Reading to Learn (Rose, 2017; Rose \& Martin 2012, 2013). Reading to Learn is a methodology that supports learners to read with comprehension and engagement, and then to use what they have learnt from reading to write coherent texts. It is also a professional learning program designed to provide teachers with skills in the methodology, and associated knowledge about pedagogy and language. The Reading to Learn methodology is not a literacy "program"; rather it is set of resources for teachers to meet the needs of their students. The resources consist of knowledge. The professional learning program includes an assessment designed to track students' literacy growth, as teachers develop their skills. In this respect, it evaluates the tasks of both language learning and language teaching, both discussed in this paper.

The methodology had its roots in the genre-based approach to writing developed from the 1980s in the "Sydney School" (Christie, 1999; Cope \& Kalantzis, 2014; Martin, 2016; Rose, 2008, 2015), and scaffolding approaches to reading (Axford, Harders, \& Wise, 20o9; Gray, 1987). These approaches were brought together in the late 199 os for an initial research project with Indigenous Australian children (Rose, 2011; Rose, Gray, \& Cowey, 1999). These students' literacy levels were on average $4-8$ years behind their non-Indigenous peers; none were reading independently before the end of grade 3 , and all secondary students were reading at junior primary levels. By the end of the project's first year, most of these students were reading at age appropriate levels, and independent evaluation showed average literacy growth at a rate normally expected over four years (McCrae et al., 200o).

Over two decades since, Reading to Learn has grown in scope as a classroom methodology and professional program for primary, secondary and tertiary teachers, and in scale across Australia (Rose \& Acevedo, 2006; Rose, Rose, Farrington, \& Page, 2008), Asia (Lin, 2016; Shum, Tai, \& Shi, 2016), Africa (Lucas,

(C) KONINKLIJKE BRILL NV, LEIDEN, 2018 | DOI: 10.1163/9789004346369_010

This is an open access chapter distributed under the terms of the prevailing CC-BY-NC License at the time of publication. 
McEwan, Ngware, \& Oketch, 2014; Makathini, 2015), and western Europe (Coffin, Acevedo, \& Lövstedt, 2013). The results of up to four times typical literacy growth rates have been consistently replicated (Culican, 2006; Rose, 2015, 2016; Rose \& Martin, 2013). Significantly for the focus of this volume, this includes many students diagnosed with learning difficulties or special needs, who on average attain acceptable writing standards for their grade levels, within one year in the program.

This chapter outlines how this growth is achieved and evaluated, but it is also concerned with why these students do not ordinarily achieve success in school. In doing so, it seeks to relate evaluation to language, language to knowledge, knowledge to pedagogy, and pedagogy to social justice. The starting point is theories: a social theory of knowledge in schools, in which students are more or less successful; a social theory of learning, in which learning emerges from the teacher/learner relation; and a functional theory of language, in which people exchange meanings through speaking or writing. The functional language model is applied to designing a writing assessment, illustrated with a student diagnosed with learning difficulties. This student's difficulties are then contextualised in a discussion of literacy development through the stages of school, and how this development differs between more and less successful students. This is followed by an examination of evaluation and pedagogy in learning theories that are focused on individual development or social learning. The chapter concludes with a brief description of the Reading to Learn pedagogy, and assessment of the same student's literacy growth following its application.

Behind each evaluation can be found a theory of learning, a theory of knowledge, and a theory of language, whether these theories are explicit or tacit. But to be clear about the evaluations we use, we do need to be explicit about the theories that inform them. Theories of learning can be contrasted between those that construe learning as intra-individual processes modelled on biological development, and those that construe learning as a social process between teachers and learners. Theories of language can be contrasted between those that focus on forms of words and syntactic rules for combining them in sentences, and those that focus on the social functions of meanings exchanged by speakers. Theories of knowledge can be contrasted between those that view knowledge as constructed by the individual and social realist theories such as that of Bernstein (2000), that view learning as an exchange of knowledge between learners and teachers. In this chapter I present an approach to evaluation based on a realist model of knowledge, a social model of learning, and a functional model of language. 


\section{Knowledge}

Bernstein's theory of knowledge is embedded in an analysis of education as a social institution in which knowledge is produced and exchanged. In this model, knowledge is understood as an evolving social resource that includes both knowledge about the natural and social worlds, and skills for acting in those worlds. Cultures can be understood as reservoirs of these resources, accumulated over many generations, from which each member gradually builds his or her own repertoire, and exchanges it with others. School knowledge is a particular reservoir of resources, from which each student builds a repertoire through education. Bernstein's theory further links pedagogic evaluation to the social distribution of resources, including knowledge. It helps to explain the tendency of schools to reproduce social inequalities, as students from lower socio-economic groups are likely to be evaluated as less successful, and given access to different kinds of knowledge than more successful students. For example, while the latter may study sciences and calculus in preparation for university, less successful students may study "life skills" and "functional maths". While the most successful may study literary criticism, the least successful may be given remedial literacy lessons.

\section{Learning}

Evaluation can also be located in a social theory of learning, in terms of the teacher/learner relation unfolding in time. Rose \& Martin (2012) propose that learning occurs through activity, that a learning task is the core element of the activity, and that only the learner can do this task. Two core roles of teachers in a learning activity are to specify the learning task (e.g., with a spoken or written question), and to evaluate its performance. What learners demonstrate in performing the task is the knowledge they have acquired; the evaluation tells them how well they have learnt. As far as we can tell, this is a fundamental structure of learning activities, in all pedagogic contexts, no matter what the learning theory. The task is the core phase. It may be done independently without any specification or evaluation, but in formal education it is usually specified and evaluated by teachers. Furthermore, a teacher may prepare learners for a task, by providing the knowledge required to do it successfully, and successful performance of a task provides a platform of understanding on which knowledge can be elaborated.

Teachers' roles in preparing, specifying, evaluating and elaborating learning tasks require a detailed understanding of the nature of the task. This is 
apparent in manual activities, in which the teacher is an expert, and guides the learner to do the activity in steps. Such modelling and guidance may be a fundamental pedagogic pattern across human cultures. But in the school, most learning activities involve language, and more often than not the task is constituted entirely in spoken or written language. Hence teachers' understanding of learning tasks in school must involve some model of language.

\section{Language}

Frequently, the model of language applied in pedagogic activities, including assessments, is the "bricks-\&-mortar" model of formal and traditional school grammars, in which words (bricks) are combined into sentences by grammatical rules (mortar), and words are composed in turn of letters representing sounds (bricks) combined by spelling rules (mortar). In various forms, this model has dominated European linguistics for two and a half millennia. The functional model of language takes a different perspective, in which language is defined as a resource for meaning, as in Bernstein's model of knowledge as reservoir and repertoire. Speaking, reading and writing involve exchanging meanings with each other. Language and its social contexts are complementary dimensions of the process of making meaning, in which language enacts relations between interactants, and construes their experience.

The language system is immensely complex, but we can describe its outlines with a few basic dimensions, highlighted in bold as follows. We can distinguish general dimensions of the social contexts of language, including the tenor of social relations, fields of social activity, and the mode of language, as dialogic or monologic, spoken or written. These three dimensions are known in systemic functional linguistics as register. A culture consists of a huge variety of options in tenor, field and mode, but these options are woven together in consistent configurations that are recognisable to members of the culture. These recognisable configurations of tenor, field, and mode are known as genres. Each genre goes through predictable stages to achieve its social purposes. For example, a narrative may expect a complicating event and a resolution, a debate expects one side to be argued, and then another side, and so on (Martin \& Rose, 2008).

A genre is realised by patterns of tenor, field, and mode, which are realised in turn as patterns of language. But language does not consist merely of words in sentences; rather social contexts unfold as text. Patterns of unfolding meanings in texts are referred to as discourse. Tenor is realised as patterns of interpersonal meaning (such as moves in a dialogue), field as ideational meaning 


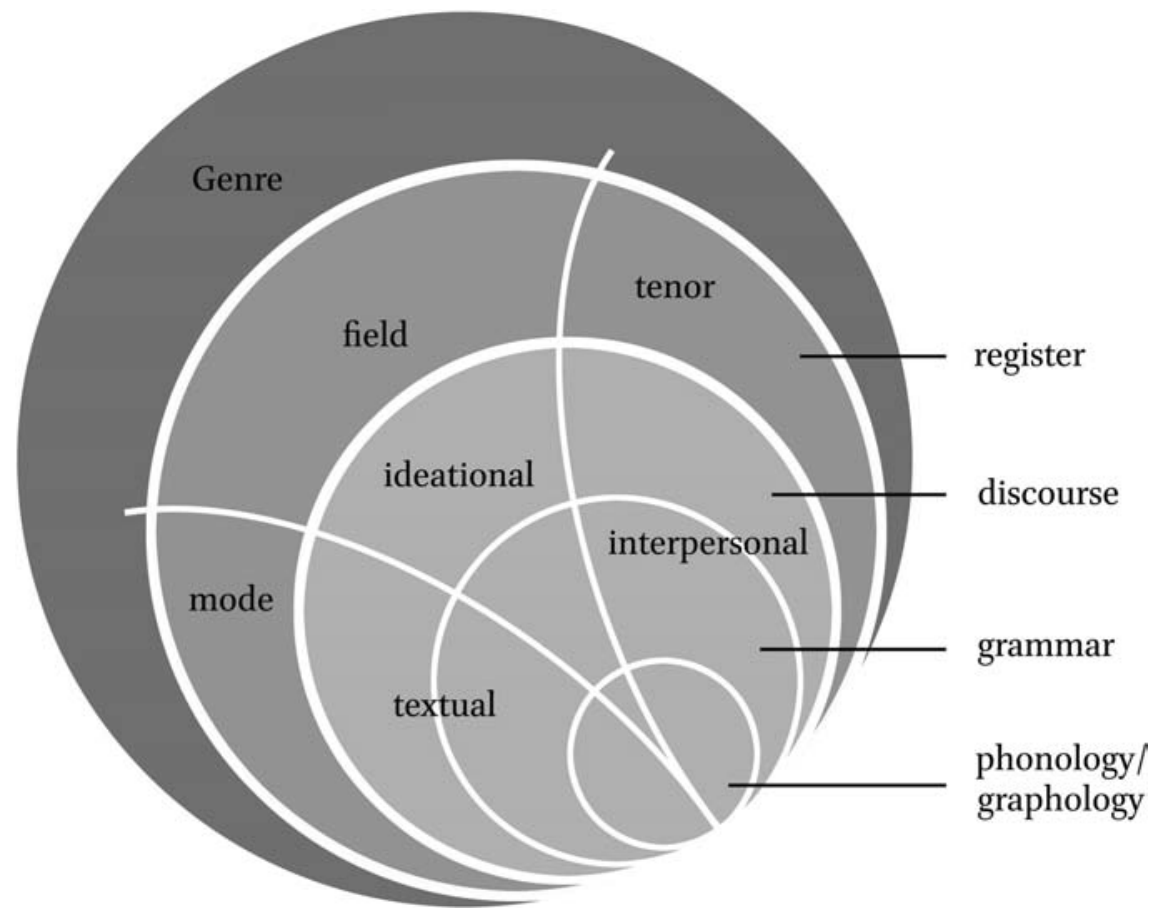

FIGURE 9.1 Language in social contexts

(such as sequences of events), and mode as textual meaning (how information is organised). These patterns of meaning in texts are realised as patterns of wording in sentences, or grammar, which are realised in turn as patterns of sounds (phonology) or letters (graphology). The whole model is illustrated in Figure 9.1.

\section{Evaluation of Language Resources}

This language model enables us to interpret learning tasks in school in terms of genre, register, and the language patterns that realise them, and to evaluate tasks in the same terms. Based on this model, a writing assessment was designed in the Reading to Learn program, to accurately analyse the language resources that each student brings to the writing task (Rose, 2015, 2016, 2017).

Teachers identify these language resources in students' writing, using 14 criteria. At the level of genre, evaluation focuses on the global social purpose of the text, and its organisation into stages, and phases within each stage. (A phase of meaning is typically expressed as a paragraph in writing.) At the level of 
register, it focuses on the text's field, tenor, and mode. At the level of discourse, interpersonal, ideational and textual features are identified. Ideational features include lexis or "content words", and conjunctions that link sequences of events. Interpersonal features include appraisal (evaluative items). Textual features include reference items (pronouns, articles). At the level of grammar, the variety and accuracy of grammatical resources are evaluated. At the level of graphic features, spelling, punctuation and graphic presentation are marked. The sequence of analysis is thus from the "top-down", from genre to register, to discourse, to grammar, to graphology. Questions are used to interrogate each of these criteria, summarised in Table 9.1.

Each criterion is scored o-3: $0=$ no evidence; $1=$ present but weak; $2=$ good but could be improved; 3 = excellent for the student's grade level. The assessment thus gives equal weight to each component of the writing task. Like all assessments it involves teacher judgements, but they are constrained to a o3 choice within each criterion.

We can use the criteria to assess the following Text 9.1, written by a 14 year old Indigenous student in Year 9. The writing task asked students to write about themselves.

In the following transcript, appraisals are underlined.

$d[$ avid $]$ the best makin poeple laugh
very cheeky when want to
can get loud and quiet
I am short temperd
david rules at chess
good at making plans

From a glance at Text 9.1, this very low assessment is intuitively predictable, but the criteria make specific weaknesses apparent. After nine years in school, this student appears to have learnt very little about written language. He is apparently unable to form legible letters, or structure and punctuate simple sentences. He apparently only has words to express simple evaluations of his personality traits. His written language resources are so far behind his grade level that mode is scored at $\mathrm{o}$. 
GENRE [Genre stages and phases can be marked and labelled.]

Purpose How appropriate and well-developed is the genre for the writing purpose?

Staging Does it go through appropriate stages, and how well is each stage developed?

Phases How well organised is the sequence of phases in each stage?

REGISTER [Quick judgements are made about these register criteria.]

Field How well does the writer understand and explain the field in factual texts, construct the plot, settings and characters in stories, or describe the issues in arguments?

Tenor How well does the writer engage the reader in stories, persuade in arguments, or objectively inform in factual texts?

Mode How highly written is the language for the school stage? Is it too spoken?

DISCOURSE [Discourse criteria are marked in the text, to give an accurate measure.]

Lexis What are the writer's lexical resources? How well is lexis used to construct the field?

Appraisal What are the writer's appraisal resources? How well is appraisal used to engage, persuade, evaluate?

Conjunction Is there a clear logical relation between all sentences?

Reference Is it clear who or what is referred to in each sentence?

GRAMMAR [Quick judgements can be made about grammar.]

Is there an appropriate variety of sentence and word group structures for the school stage? Are the grammatical conventions of written English used accurately?

\section{GRAPHIC FEATURES}

Spelling How accurately spelt are core words and non-core words?

Punctuation How appropriately and accurately is punctuation used?

Presentation Are paragraphs used? How legible is the writing? Is the layout clear? Are illustrations/diagrams used appropriately? 


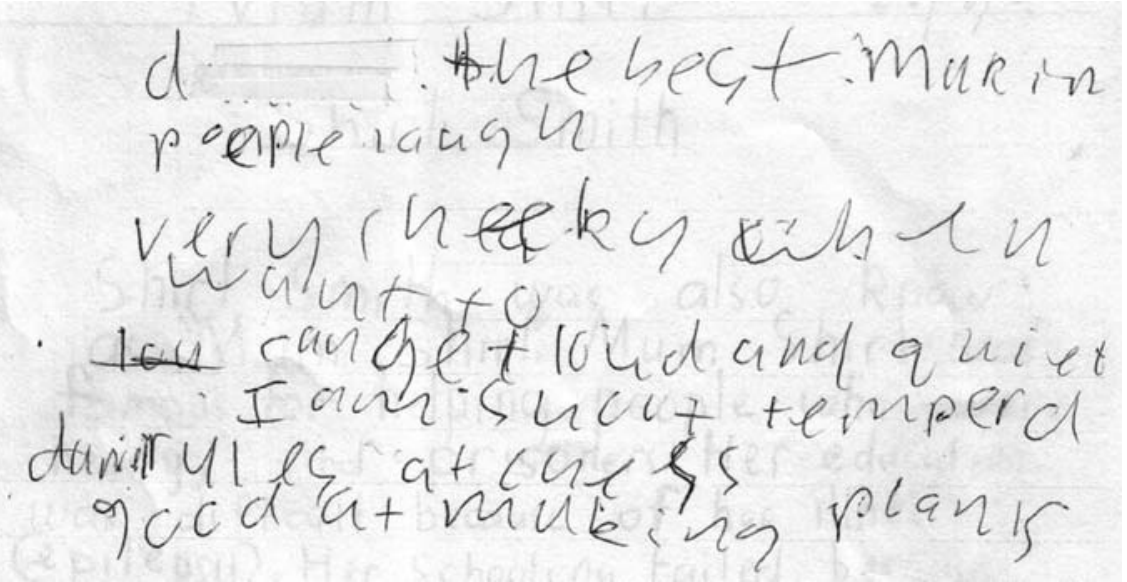

TEXT 9.1 Yeargstudent

TABLE 9.2 Assessment of Text 9.1

\section{Criteria}

Purpose

Staging

Phases

Field

Tenor

Mode

Lexis

Appraisal

Conjunction

Reference

Grammar

Spelling

Punctuation

Presentation

\section{Comments}

$$
\begin{array}{ll}
1 & \text { personal description-very simple } \\
\text { o } & \text { no stages } \\
\text { O } & \text { no phases } \\
1 & \text { brief personal knowledge } \\
1 & \text { simple personal evaluations } \\
\text { o } & \text { far too spoken for Year } 9 \text {-Year } 1 \text { standard } \\
1 & \text { only two items - chess, plans } \\
1 & \text { simple judgements (underlined) } \\
\text { O } & \text { no conjunction—-simple list } \\
1 & \text { only two personal references-I, david } \\
\text { O } & \text { very simple, many missing items } \\
1 & \text { most common words correct, some errors } \\
\text { O } & \text { no punctuation or letter cases }
\end{array}
$$$$
\text { o no stages }
$$$$
\text { o no phases }
$$

Total 7/42 well below grade standard 


\section{Evaluation and Literacy Development through School}

This student's apparent inability to learn basic components of written language led to classifications of "learning disabilities" and "special needs", for which he has been prescribed remedial literacy programs throughout his schooling. As he has been unable to read curriculum texts independently, most school knowledge has been closed to him. As he lacks such knowledge, he has been unable to participate actively in classroom learning. Years of continual failure contributed to behaviour problems that led to his placement in a special program for such students, in which he was subject to further remedial literacy programs. His attempt in Text 9.1 illustrates the educational outcome of this nine year history.

These types of remedial literacy interventions tend to be informed by the reductive model of language as bricks-\&-mortar. They "dis-integrate" the language learning task, isolating low level grammatical and graphological components from the higher strata of meaning making. Struggling readers and writers tend to experience these activities as meaningless drills, with little discernible relation to meaningful communication. Indigenous and other children struggling to read and write can be seriously disadvantaged by these approaches (Rose et al., 1999). Such students may appear to teachers and specialists to lack perceptual, cognitive, and motor skills, but these may be merely symptoms of problems that originate with ineffective teaching.

The sequence of development in reading and writing skills through each stage of school has been referred to as a "hidden curriculum" (Rose, 2004). For successful students, each stage prepares them for the reading and writing tasks of the next stage. But as these tasks become more and more elaborate, there is less and less explicit teaching of the literacy skills involved. Indeed, it is only in the junior primary that foundation skills in reading and writing are explicitly taught. If children do not adequately acquire these skills in this initial stage, they will not be prepared for the next stage. They may be given remedial literacy activities in subsequent stages, but they are unlikely to catch up to their more successful peers. While each stage prepares successful students for the next, all students are evaluated on how well they acquired skills in the preceding stages.

In this hidden curriculum, successful students tacitly acquire skills in each stage, building on skills they acquired in preceding stages. One outcome is that the gap between most and least successful students is maintained throughout the whole of schooling. This pattern is graphically illustrated in Figure 9.2, which aggregates writing assessments from teacher training in the Reading to Learn program. Teachers are asked to assess writing samples from students in top, middle, and bottom groups in their classes, before implementing the 


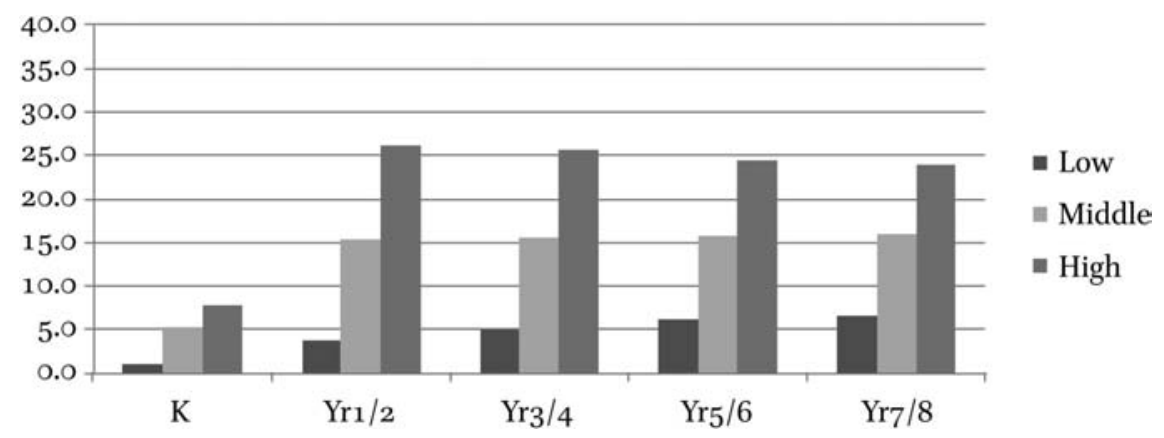

FIGURE 9.2 Pre-intervention scores show gap between student groups before R2L teaching. Figure 9.2 represents students' average writing skills without receiving Reading to Learn strategies. These pre-intervention results function as the 'control'for measuring the effectiveness of the intervention. Results are shown for each stage of school, from kindergarten through junior, middle and upper primary to junior secondary school. For each school stage, results are averaged for students in lower, middle and upper achievement bands. Results are measured on 14 criteria covering knowledge and language skills, each scored o-3, giving a possible total of 42 represented on the $\mathrm{Y}$-axis.

Reading to Learn literacy strategies. Figure 9.2 shows results for these "pre" samples, averaged across assessments by 400 teachers in one training program in 2010, representing at least 10,0oo students (Rose, 2015, 2016; Rose \& Martin, 2012, 2013).

Figure 9.2 is useful because it shows the mean differences in written language resources of high, middle and low achieving student groups in each school stage. As this is a large sample across classes and schools, it may be read as approximating differences in the Australian and similar education systems. What is particularly interesting is that the gap between top and bottom groups is comparatively narrow at the start of school, labelled $\mathrm{k}$ for kindergarten, but after a year or two the gap has tripled, and remains steady through each following school stage. The top group has clearly benefited from the literacy practices of their early-years teachers, as their average results have shot up to the median standard for the school stage. These children are now reading and writing independently, and are likely to be actively engaged in learning from reading. The middle group has also obtained some benefit, but the bottom group appears to have received very little benefit from these literacy practices; their results are still near zero, and improve only slightly through each subsequent stage. The children who were failing at the start of primary school are still failing at the start of secondary, despite all the interventions prescribed by various literacy theories. These large-scale data confirm what teachers know intuitively, that the gap between the top and bottom students in their classes 
and schools will essentially be the same at the end of each year, and each student's school career, as it was at the start.

\section{Evaluation in a Social Learning Theory}

Vygotsky's famous zone of proximal development (ZPD) refers to a contrast between two modes of evaluation, independent or guided. He defines ZPD as "the distance between the actual development level as determined by independent problem solving and the level of potential development as determined through problem solving under adult guidance or in collaboration with more capable peers" (1978, p. 86). Assessment of actual development is of course what most school assessments are concerned with, in order to rank students and determine their education programs, pathways and outcomes, as discussed above. Concomitantly, independent problem solving is the ideal learning activity in individuated pedagogies.

In these theories and practices, the ideal learning activity is one in which students are doing learning tasks (solving problems) individually. As the task is done independently, its difficulty must be close to students' assessed learning abilities. As they complete each task, their performance may be evaluated. If they are successful, they may be deemed ready for a further learning task that is just beyond their new competence, and the cycle continues for that task. High achieving students are given more complex tasks at each step, and low achieving students are given simpler tasks. In addition, the pacing of the high group's learning may be faster, and the pacing of the lower group's learning slower. This is the trend we see demonstrated statistically in Figure 9.2. The gap is maintained through each year, each school stage, and the whole sequence of schooling. It is reproduced by constraining students' development to their assessed ability levels. It is simultaneously legitimated by these assessments, as though "ability" was a natural explanation of unequal outcomes. Bernstein for one does not accept this explanation:

The school must disconnect its own internal hierarchy of success and failure from ineffectiveness of teaching within the school and the external hierarchy of power relations between social groups outside the school. How do schools individualize failure and legitimize inequalities? The answer is clear: failure is attributed to inborn facilities (cognitive, affective) or to the cultural deficits relayed by the family which come to have the force of inborn facilities.

200o, p. xxiv 
Bernstein's conclusion proposes a radically different explanation: rather than inborn facilities, the cause of failure and inequality is "ineffectiveness of teaching". This explanation shifts the focus of evaluation from the individual learner onto the teaching practice, in other words, onto the pedagogic relation between learner and teacher. This is Vygotsky's second option for evaluation, the learner's potential development as determined through problem solving under adult guidance. This potential development is the knowledge/skills that are possible for a learner to acquire with effective teaching. From the perspective of knowledge and pedagogy, the ZPD is the difference between what a learner already knows, and the knowledge he or she could be taught. This is a radically different view of knowledge and pedagogy from individualist theories. Vygotsky is quite explicit about this:

Any function in the child's cultural development appears twice, or on two planes. First it appears on the social plane, and then on the psychological plane. First it appears between people as an inter-psychological category, and then within the child as an intra-psychological category.

$$
\text { 1981, p. } 163
$$

In other words, the notion of learners constructing knowledge individually is an illusion. All cultural development, i.e., knowledge, begins with the pedagogic relation between learner and teacher. It is through this relation that the culture's reservoir of semiotic resources is negotiated, in order to build the learner's repertoire.

\section{From Evaluation to Pedagogy}

If we can accept Bernstein's and Vygotsky's propositions, then any assessment is not merely an evaluation of individual learners' abilities; what it actually evaluates is the effectiveness of teaching that learners have experienced. If students are failing in school, such as the writer of Text 9.1, then their teaching has been ineffective. This is not to say that the teaching is ineffective for all, but that it is less effective for some students than for others, creating and reproducing inequalities. The important question for evaluation of struggling students is then not what skills the learner lacks, but what factors make teaching ineffective. Clearly if the role of the teacher is constrained, as in some constructivist pedagogies, this would be one factor. Where the teacher does have a clear authoritative role, another potential factor is a failure to understand the learning task, and another is a failure to design effective preparations for learners to do the task successfully. 
As all learning tasks in school involve language, particularly reading and writing, and language is such an immensely complex phenomenon, it is hardly surprising that learning tasks are often poorly understood and their preparations often poorly designed. The problem is compounded by the bricks-\&mortar language model that often informs both assessments and remedial interventions, divorcing language learning from curricular learning. An alternative is provided by the Reading to Learn methodology, which is informed by the functional model of language and social learning theory (Rose \& Martin, 2012). In this approach, learning language is integrated with curricular knowledge, reading is integrated with writing, and teachers design preparations to enable all students to do the same tasks successfully.

Effective design of preparations can support students to succeed with learning tasks that are well beyond their independent capacities. Supported success with high level tasks can accelerate learning faster than independent practice with lower level tasks, as it targets learners' potential development, systematically guiding them to acquire new skills. The ZPD is larger for some students than others. If they are then assessed, the performance of both groups will be lower than the supported task level, but the growth will be greater than with independent practice. If students are then supported with a further high level task, their following assessments will again fall below the supported level, but will be higher than their previous assessments. As cycles of supported tasks are repeated, the skill levels of weaker students accelerate faster than those of stronger students, and the gap between them narrows.

In Reading to Learn, students are supported with tasks that may be well beyond their independent competences, through a carefully designed sequence of reading and writing activities informed by the functional language model. The first activity, known as Preparing for Reading, supports students to follow a text with general comprehension as it is read aloud, by the teacher orally summarising the sequence in which it unfolds, in terms that all students can understand. As the field of the text is prepared, all students know what to expect and need not struggle to comprehend as it is read. Because it is read aloud, they need not struggle to decode unfamiliar written words. This massively reduces the load of the reading task, enabling even the weakest students to focus on the unfolding meanings in challenging texts. The next activity, Detailed Reading, supports all students to visually read passages of the text with detailed comprehension, by guiding them to identify wordings in each sentence, highlight them, and discuss their meanings. As they already have a general understanding of the text, the load of recognising words is reduced, enabling all students to comprehend their meanings in detail, and read the passage fluently. 
To provide more support, Detailed Reading may be followed by Sentence Making, in which the teacher writes sentences from the Detailed Reading passage on cardboard strips, and guides students to cut them into chunks of meaning and manually manipulate them. This manual practice gives students total control over words and meanings. It is particularly effective for young or struggling students. Sentence Making then leads to Spelling, in which individual words are cut into their letter patterns, which students practise writing on small whiteboards. They then practise using these words in Sentence Writing on their whiteboards. Sentence Making, Spelling, and Sentence Writing are key strategies for students diagnosed with special needs. Rather than drilling foundation skills in isolation, they are practised in the meaningful context of texts, passages, and sentences that students understand and are engaged in, which rapidly accelerates their learning.

In the next activity, Joint Rewriting, students are guided to write a new passage, using what they have learnt from Detailed Reading. For stories, rewriting follows the precise language patterns of the reading passage, but changes the plot, setting, and characters. This supports students to use the language resources of accomplished authors in their own writing. For factual texts, rewriting begins by students writing notes on the class board from the information that has been highlighted in the reading text. The teacher then guides the class to use this information in a new passage. Finally, after building knowledge and language resources through this sequence of activities, the teacher guides students to construct whole new texts, in the activity known as Joint Construction. The sequence thus follows the functional language model, focusing on each component of the language task from the top down, beginning with genre and register in Preparing for Reading, followed by discourse and grammar in Detailed Reading, then graphology in Sentence Making, Spelling, and Sentence Writing. It then builds back up through the model, through grammar and discourse in Joint Rewriting, to genre and register in Joint Construction. Relations between levels of the language task and the teaching sequence are illustrated in Figure 9.3.

These activities are repeated through daily, weekly and monthly cycles, as the school program permits, embedding literacy learning in curriculum teaching. Students' literacy growth can be extremely rapid with consistent practice. Text 9.2 was written by the same student as Text 9.1, after a few weeks of these activities. It is a brief biography of the Indigenous Australian leader, Shirley Smith, or "Mum Shirl". It was written independently, following a series of whole class activities, studying biographies of Mum Shirl, and practising writing. 
EVALUATING THE TASK OF LANGUAGE LEARNING

175

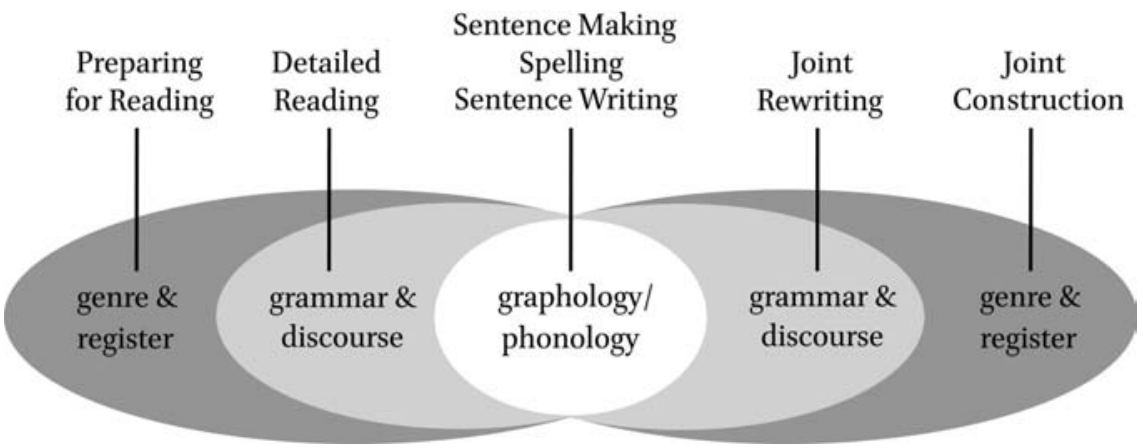

FIGURE 9.3 Reading to Learn sequence and language levels

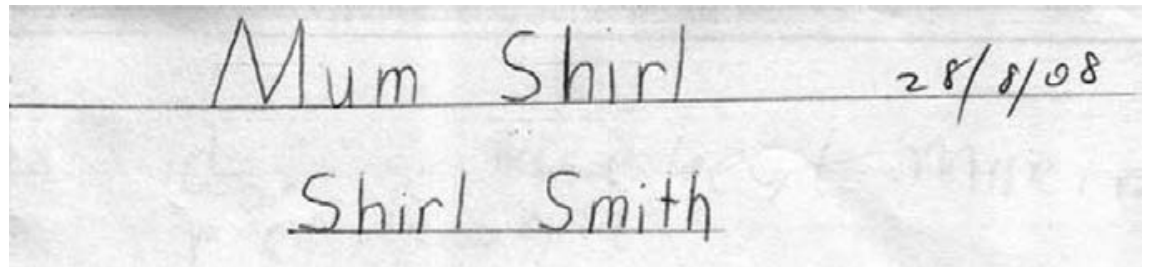

Shicl Smith was also know as "Mum Shirt. Mum Shirt was famous for helping people who were needy, and prisoners. Her education was difficult because of her illness (epilepsy). Her schooling failed because She couldn't go to school. Back then times were difficult for aboriginal people. They took away your children. It was hard to trust anybody after it Mum Shirt helped people become happy and comfortable. She fought for others. She helped others get on with their lives.

TEXT 9.2 Same student following intervention

David Rose - 9789004346369

Downloaded from Brill.come4/26/2023 02:13: ०9AM

via free access 


\section{Criteria Comments}

\begin{tabular}{|c|c|c|}
\hline Purpose & 1 & biography-simple \\
\hline Staging & 1 & brief Orientation, no Life stages \\
\hline Phases & 1 & $\begin{array}{l}\text { clear phases-identity, early life, social context, life } \\
\text { work }\end{array}$ \\
\hline Field & 1 & $\begin{array}{l}\text { Mum Shirl's work, early life, social context, but no } \\
\text { detail of life }\end{array}$ \\
\hline Tenor & 1 & objective evaluations \\
\hline Mode & 1 & written language - middle primary standard \\
\hline Lexis & 1 & $\begin{array}{l}\text { builds simple field-prisoners, education, epilepsy, } \\
\text { schooling, Aboriginal people }\end{array}$ \\
\hline Appraisal & 1 & $\begin{array}{l}\text { positive judgements of Mum Shirl, evaluates problems } \\
\text { of Aboriginal people }\end{array}$ \\
\hline Conjunction & 1 & $\begin{array}{l}\text { reasons-because, historical sequence-back then, } \\
\text { after it }\end{array}$ \\
\hline Reference & 1 & $\begin{array}{l}\text { keeps track with pronouns-she, her, it, their, and } \\
\text { comparison-others }\end{array}$ \\
\hline Grammar & 1 & appropriate but relatively simple \\
\hline Spelling & 2 & variety of words correct \\
\hline Punctuation & 2 & correct punctuation and letter cases \\
\hline Presentation & 1 & legible handwriting, no paragraphs for phases \\
\hline
\end{tabular}

Shirl Smith was also know as "Mum Shirl". Mum Shirl was famous for helping people who were needy, and prisoners. Her education was difficult because of her illnes (epilepsy). Her schooling failed because she couldn't go to school. Back then times were difficult for aboriginal people. They took away your children. It was hard to trust anybody after it. Mum Shirl helped people become happy and comfortable. She fought for others. She helped others get on with their lives.

The assessment in Table 9.3 shows consistent improvements in all areas of genre, register, and language. A glance at the text shows that grammar and performance on graphic criteria are vastly improved compared to Text 9.1. This is not a result of drilling these features, as in remedial literacy programs. 
Rather it is an effect of gaining control of higher level features-genre, register, discourse - and practising grammar and graphic features in this meaningful context. However the student's language resources are still weak in most areas, below the standard expected for middle secondary school. This is not surprising, considering how much further Text 9.1 was below the standard. What may be surprising is the extraordinary gains this student has made in just a few weeks, after nine years of failure. Crucially these gains were not achieved by the student alone, but with the support of the teacher with the whole class. Text 9.2 demonstrates growth after one or two iterations of supported practice with high level tasks.

Figure 9.4 shows results for the same teachers and students as Figure 9.3, after 6-8 months of Reading to Learn training and classroom practice. Comparing results between Figures 9.3 and 9.4, post-intervention scores show average growth in kindergarten to be $70 \%$ above pre-intervention scores; all groups are now scoring in the high range, and the gap between low and high achieving groups is halved. In the other year levels, growth is $30-40 \%$ above the preintervention scores, and the gap has halved from $50 \%$ to around $25 \%$. These results were achieved after three or more iterations of supported practice, as outlined above. Crucially they were achieved mainly by teachers working with whole classes. Although Reading to Learn can be used for additional support with groups or individual students, Culican (2006) reported that the whole class model of delivery produced better outcomes than were obtained using withdrawal groups. While the ZPD is much larger for weaker than for stronger students, the Reading to Learn strategies support all students to do the same high level tasks together.

\section{Conclusion}

There is no question that a proportion of school students diagnosed with learning difficulties may have significant neurological impairments that constrain their capacity to develop as readers and writers. But in my experience working with teachers of Indigenous and other groups of students diagnosed with learning difficulties, the problem is overwhelmingly not neurological but pedagogic; the failure is not in the student but in the effectiveness of teaching. I have argued in this paper that such ineffective teaching practices stem from an individuated view of learning that fails to properly analyse the nature of learning tasks, and hence fails to design effective preparations for learners to succeed with tasks. These failures in analysis and design are partly the result of a reductive bricks-\&-mortar model of language that "dis-integrates" the lan- 


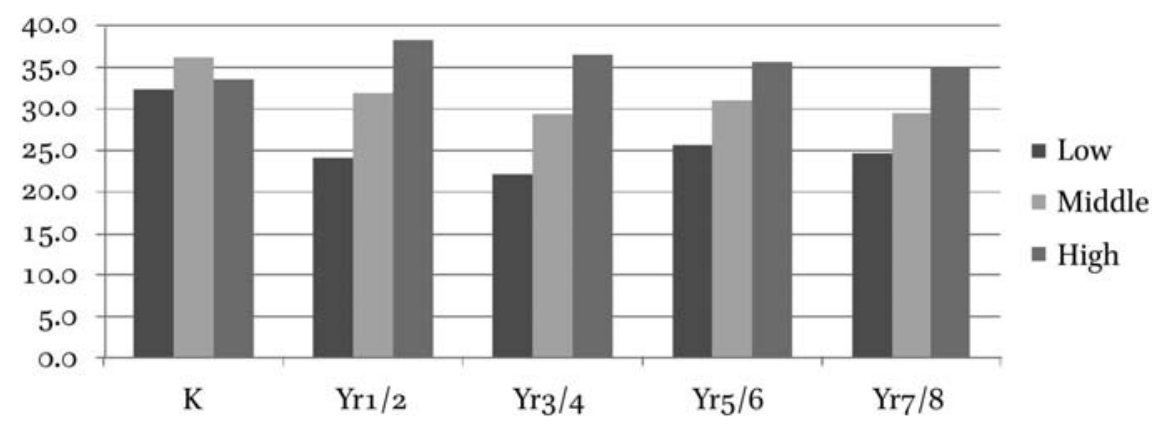

FIGURE 9.4 Post-intervention scores show gap between student groups after R2L teaching. Figure 9.4 shows results for the same students as represented in figure 9.2 and the same teachers as they trained and applied the strategies for about 6 months, with their whole classes. Results are measured on 14 criteria covering knowledge and language skills, each scored ${ }^{-}-3$, giving a possible total of 42 represented on the $Y$ axis and are shown for each stage of school, from kindergarten through junior, middle and upper primary to junior secondary school (x-axis).

guage learning task, and focuses on the lowest levels of language, prescribing remedial literacy activities that are unlikely to ever enable struggling students to catch up with their more successful peers.

The evidence of assessments presented in this chapter indicates that such remedial interventions have minimal effects on the inequality of learning and outcomes in schools. Students who are evaluated in the failing range at the start of school are likely to remain in this group through each stage of primary and secondary, despite incremental improvements that may be attributed to remedial activities. With regard to the so-called "gold standard" of education research using randomised trials with control groups (Mertens, 2014), the preintervention assessments shown in Table 9.2 function as the counterfactual in the Reading to Learn research. These pre-intervention results represent the sum of the effects of prior literacy teaching and remedial interventions for the top, middle and bottom cohorts in each stage of schooling, using a sample of over 10,00o students. Although this data is cross-sectional, this data gives the reader a sense for the expected learning gains experienced by similar peers. As such, they are proxy measures of the average effectiveness of teaching practices other than the Reading to Learn methodology. Their persistence year-after-year correlates with Bernstein's interpretation, that continual failure is an endemic pattern of the school, which "necessarily produces a hierarchy based on success and failure of students" (Bernstein, 2000, p. xxiv).

If the problem lies with the school, the solution cannot be found by attempting to remediate the difficulties of individual students. If we are serious about solving these difficulties, we must look to teaching practices of the school that 
create and maintain inequalities, and re-design these practices. This has been the approach of Reading to Learn, which uses a functional model of language to integrate language learning tasks in carefully designed sequences of activities, and uses a social model of learning to guide all students in a class to practice high level reading and writing tasks, no matter what their assessed "abilities". The writing assessment, which is integral to the professional learning program, shows the full range of language resources that students bring to the writing task. It also shows the power of the methodology to narrow the achievement gap between the most successful and least successful students, including those diagnosed with learning difficulties. Since it is their teachers who have enabled students to achieve these gains, it evaluates success, not only with the tasks of language learning, but with the tasks of language teaching.

\section{References}

Axford, B., Harders, P., \& Wise, F. (2009). Scaffolding literacy: An integrated and sequential approach to teaching reading, spelling and writing. Canberra: Australian Council for Education Research.

Bernstein, B. (2000). Pedagogy, symbolic control and identity: Theory, research, critique. London \& Bristol, PA: Taylor \& Francis. [Revised edition, Lanham, Maryland: Rowan \& Littlefield.

Christie, F. (Ed.) (1999). Pedagogy and the shaping of consciousness: Linguistic and social processes. Open Linguistics Series. London: Cassell.

Coffin, C., Acevedo, C., \& Lövstedt, A-C. (2013). Teacher Learning for European Literacy Education (TeL4ELE) Final Report. Geneva: European Union, http://tel4ele.eu/

Cope, B., \& Kalantzis, M. (2014). The powers of literacy (RLE Edu I):A genre approach to teaching writing. London: Routledge.

Culican, S. (2006). Learning to read: Reading to learn, a middle years literacy intervention research project, Final Report 2003-2004. Catholic Education Office: Melbourne. http://www.readingtolearn.com.au

Gray, B. (1987) How natural is "natural" language teaching? Employing wholistic methodology in the classroom. Australian Journal of Early Childhood, 12(4), 3-19

Lin, A.M. (2016). Language across the curriculum \& CLIL in English as an Additional Language (EAL) contexts: Theory and practice. Springer.

Lucas, A.M., McEwan, P.J., Ngware, M., \& Oketch, M. (2014). Improving early-grade literacy in east Africa: Experimental evidence from Kenya and Uganda. Journal of Policy Analysis and Management, 33(4), 950-976.

McRae, D., Ainsworth, G., Cumming, J., Hughes, P., Mackay, T. Price, K., Rowland, M., Warhurst, J., Woods, D., \& Zbar, V. (200o). What has worked, and will again: The 
IESIP strategic results projects (pp. 24-26). Canberra: Australian Curriculum Studies Association.

Makathini, B. (2015) Trampoline trajectories: A dialectical analysis of the correlation between the teaching of reading and the learner-academic performance in a South African rural primary school. Ph.D. Thesis. University of KwaZulu-Natal, South Africa

Martin, J.R. (2016). One of three traditions: Genre, functional linguistics and the "Sydney School". In N. Artemeva (Ed.), Trends and tradition in genre studies (pp. 31-79). Ottawa: Inkwell.

Mertens, D.M. (2014). Research and evaluation in education and psychology: Integrating diversity with quantitative, qualitative, and mixed methods. Washington, DC: Sage Publications.

Rose, D. (2004). Sequencing and pacing of the hidden curriculum: How Indigenous children are left out of the chain. In J. Muller, A. Morais, \& B. Davies (Eds.), Reading Bernstein, researching Bernstein (pp. 91-107). London: Routledge Falmer.

Rose, D. (2008). Writing as linguistic mastery: The development of genre-based literacy pedagogy. In R. Beard, D. Myhill, J. Riley, \& M. Nystrand (Eds.), Handbook of writing development (pp. 151-166). London: Sage.

Rose, D. (2011). Beating educational inequality with an integrated reading pedagogy. In F. Christie \& A. Simpson (Eds.), Literacy and social responsibility: Multiple perspectives (pp. 101-115). London: Equinox.

Rose, D. (2015). New developments in genre-based literacy pedagogy. Handbook of writing research, 2nd Edition. New York: Guilford.

Rose, D. (2016). Engaging children in the pleasures of literature and verbal art. English in Australia, 51(2), 52-62.

Rose, D. (2017). Reading to Learn: Accelerating learning and closing the gap. Sydney: Reading to Learn. http://www.readingtolearn.com.au

Rose, D., \& Acevedo, C. (2006). Closing the gap and accelerating learning in the middle years of schooling. Literacy learning: The middle years, 14(2), 32-45.

Rose, D., Gray, B., \& Cowey, W. (1999). Scaffolding reading and writing for Indigenous children in school. In P. Wignell (Ed.), Double power: English literacy and Indigenous education (pp. 23-6o). Melbourne: National Language \& Literacy Institute of Australia (NLLIA).

Rose, D. \& J.R. Martin (2012). Learning to write, reading to learn: Genre, knowledge and pedagogy in the Sydney School. London: Equinox.

Rose, D. \& J.R. Martin (2013). Intervening in contexts of schooling. In J. Flowerdew (Ed.), Discourse in context: Contemporary applied linguistics, Volume 3 (pp. 447-475). London: Continuum.

Rose, D., Rose, M., Farrington, S., \& Page, S. (2008). Scaffolding academic literacy with indigenous health sciences students: An evaluative study. Journal of English for Academic Purposes, 7(3), 165-179. 
Shum, M.S.K., Tai, C.P., \& Shi, D. (in press). Using "Reading to Learn" (R2L) pedagogy to teach discussion genre to non-Chinese-speaking students in Hong Kong. International Journal of Bilingual Education and Bilingualism. http://dx.doi.org/10.1080/ 13670050.2016.1159653

Vygotsky, L. (1978). Mind in society: The development of higher psychological processes. Cambridge, MA: Harvard University Press.

Vygotsky, L.S. (1981). The genesis of higher mental functions. In J. Wertsch (Ed.), The concept of activity in Soviet psychology (pp. 144-188). Armonk: M.E. Sharp. 